\title{
Hazardous Alcohol Consumption and the Risk of Hearing Impairment in Adults Based on the Korean National Health and Nutrition Survey: A Retrospective Study
}

\author{
Jin-A Park and Michelle J. Suh \\ Department of Otorhinolaryngology, Jeju National University College of Medicine, Jeju, Korea
}

\section{Received May 28, 2018 \\ Revised August 2, 2018 \\ Accepted October 3, 2018}

\section{Address for correspondence Michelle J. Suh, MD \\ Department of Otorhinolaryngology, Jeju National University \\ College of Medicine, \\ 15 Aran 13-gil, Jeju 63241, Korea \\ Tel +82-64-717-1167 \\ Fax $+82-50-479-5872$ \\ E-mail myzetapotential@gmail.com}

Background and Objectives: To investigate the relationship between hearing impairment and alcohol drinking patterns in South Korean adults. Subjects and Methods: Data collection was performed by Korean National Health and Nutrition Survey from January 1 to December 31, 2012. Data analyses were performed from February 20 to March 3, 2018. Data from 3,860 adults 20 years of age or older without a history of malignancy or chronic otitis media in the Korean National Health and Nutrition Survey 2012 database who participated in the health questionnaires, and who had available results from otologic examinations that included pure tone audiogram, were included. Pure-tone average hearing thresholds were calculated at 500, $1,000,2,000$, and $4,000 \mathrm{~Hz}$. Hearing loss was defined as a pure-tone average $>40 \mathrm{~dB}$ in one or both ears. The Alcohol Use Disorder Identification Test was used to evaluate drinking statuses of subjects. Data were analyzed using the complex-sample $\chi^{2}$-test of independence and a complex-sample logistic regression analysis. Results: Of the 29,954,319 individuals in the weighted cross-sectional study population, $15,106,040$ (50.4\%) were men and $14,848,098(49.6 \%)$ were women. A total of $8.1 \%$ of men and $7 \%$ of women had hearing impairment. The degrees of drinking with appropriate, risky, and hazardous drinking habits were 58.2, 32.1, and 9.7\% among men; and 76.4, 12.5, and 11.1\% among women, respectively. Among men, the odds ratio of hearing loss increased by 2.506 times when comparing hazardous and appropriate drinking (confidence interval, 1.083 to $5.800, p=0.002$ ). Moderate alcohol consumption ( $\leq 2$ drinks per day) was not protective for hearing in either group. Conclusions: As hazardous drinking tends to coexist with hearing impairment in men, appropriate prevention and intervention strategies should be emphasized. A longitudinal study to investigate harmful drinking and the mechanism of hearing loss should be performed.

J Audiol Otol 2019;23(2):63-68

KEY WORDS: Hearing loss · Alcoholism · Longitudinal studies · Deafness · Prevalence · Risk factors · Alcohol drinking.

\section{Introduction}

Hearing loss is one of the most common health problems worldwide. Hearing loss may result from genetic causes, complications at birth, certain infectious diseases, chronic ear in-

This is an Open Access article distributed under the terms of the Creative Commons Attribution Non-Commercial License (https://creativecommons.org/licenses/by-nc/4.0/) which permits unrestricted non-commercial use, distribution, and reproduction in any medium, provided the original work is properly cited. fections, the use of particular drugs, exposure to excessive noise, and aging [1]. In addition, socioeconomic factors and health-related factors affecting hearing have been studied [2-4]. Alcohol consumption is known to be a major modifiable factor related to health [5]. The amount of alcohol consumption as well as drinking patterns are known to affect alcohol-induced damage $[5,6]$. Since excessive drinking affects physical and mental health, the World Health Organization (WHO) has developed the Alcohol Use Disorder Identification Test (AU- 
DIT) as a method of screening for excessive drinking and preventing the occurrence of diseases [7]. The research has been inconsistent regarding the relationship between hearing and drinking. Some research found a protective effect of proper drinking against hearing loss, which was explained to be similar to the cardioprotective effects of alcohol $[8,9]$. However, other research did not show any significant association between alcohol consumption and hearing loss $[10,11]$. As drinking has different cultural characteristics in each society, it is also necessary to consider ethnic differences in alcohol pharmacodynamics [12]. The current status of adult consumption in Korea is known to be high. More than $90 \%$ of Korean workers are exposed to alcohol and more than $60 \%$ experience alcohol-related problems [13]. In 2010, the monthly drinking rate among Korean adults was $77.7 \%$ for men and $41.3 \%$ for women, which was higher than the rates in the U.S. (59.2\% for men and $43.4 \%$ for women). Furthermore, the drinking behaviors and alcohol metabolism of men and women are quite different; the relationship between drinking and hearing loss needs to be analyzed in the sexes separately $[14,15]$.

This study commenced because it was required to investigate the present hearing health status according to the increasing rate of drinking in Korea. This study aimed to provide basic data to develop hearing health-promotion practices related to alcohol drinking.

\section{Subjects and Methods}

\section{Study design, setting, and participants}

The National Health and Nutrition Survey is conducted by the Disease Control Headquarters and aims to produce nationwide statistics to identify the health and nutritional statuses of Koreans. This study was based on data from the National Health and Nutrition Survey, a cohort surveyed after sampling using the stratified cluster extraction method for the whole population of Korea and was conducted in 2012. This study included a total of 3,860 subjects aged 20 years and over without malignant tumors or chronic otitis media-representing a South Korean population of 29,954,319-who were evaluated using pure-tone audiograms to determine hearing level.

\section{Ethical considerations}

The Korea Center for Disease Control and Prevention (KCDC) Institutional Reviews Board approved all survey protocol (2012-01EXP-01-2C), and participants provided informed consent before the study, which was conducted in accordance with the ethical principles of the Declaration of Helsinki.

\section{Variables: definition of hearing loss}

The hearing threshold was evaluated by trained otolaryngologists using an automatic audiometer (GSI SA-203, Entomed Diagnostics AB, Lena Nodin, Sweden) in a soundproof booth. As the WHO defines disabling hearing loss as a hearing threshold $>40$ decibels $(\mathrm{dB})$ in the better-hearing ear in adults, hearing loss was defined on the basis of which mean values of pure-tone sounds at the minimum thresholds of 500, $1,000,2,000$, and $4,000 \mathrm{~Hz}$ could be heard at $>40 \mathrm{~dB}$ in the ear with better hearing [1].

\section{Data sources/measurement: AUDIT (Korean version) questionnaire}

Among the health questionnaires, the drinking questionnaire was the self-reported type and the other items were obtained through interviews. From those, the AUDIT score was calculated, which was developed and published by the WHO to quickly and easily search for drinkers with dangerous drinking patterns [7]. The questionnaire consists of questions regarding drinking quantity and patterns, including frequency of high-risk drinking, feelings of guilt after drinking, inability to remember, or injury because of drinking, with a maximum score of 40 . All items except the age at which the subject started drinking are based on drinking during the last year. The scores were categorized as follows: the lowest score, $0-9(0-5$ for women), was defined as normal drinking habits (AUDIT grade I); $10-19$ (6-9 for women) was defined as dangerous drinking habits (AUDIT grade II); and 20-40 (10-40 in women) was defined as hazardous drinking habits (AUDIT grade III).

\section{Statistical methods, bias, and quantitative variables}

PASW Statistics 18 (SPSS Inc., Chicago, IL, USA) was used for the statistical analysis. The statistical analysis was carried out using weighting according to the guidelines for the use of primitive data by the Centers for Disease Control (CDC). Categorical variables are expressed as the percentage. Factors related to hearing loss were analyzed by dividing the study population into two groups: men and women. The chi-squared test was used to compare the prevalence of hearing loss among categorical groups according to sex. A complex-sample plan file was designed to apply $\mathrm{k}$ strata, primary sample units, and the proper use of sampling weight values. The relationship between drinking characteristics and hearing loss was investigated after correcting for confounding factors such as age, education level, household income, tinnitus, history of exposure to noise, smoking status, and presence of hypertension (HTN) or diabetes mellitus (DM); the logistic regression analyses were performed separately for the men and women. A $p$-value $\leq 0.05$ 
was considered to be statistically significant.

\section{Results}

Of the 3,860 (29,954,319, weighted) selected subjects, 1,525 (50.4\%, 15,106,040, weighted) were men and 2,335 (49.6\%, $14,848,098)$ were women. As shown in Table 1, hearing-re- lated health characteristics, and hearing loss of the men and women were analyzed as follows. Overall, the weighted prevalence of hearing loss was $8.1 \%$ in men and $7 \%$ in women. The mean age was significantly older in the hearing-impaired group. Among adults, the weighted prevalence of hearing loss was most frequent at the lowest educational level $(36.8 \%$ in men, $64.3 \%$ in women). The distribution of household income

Table 1. The characteristics of the subjects according to $\mathrm{HI}$ by sex

\begin{tabular}{|c|c|c|c|c|c|c|}
\hline \multirow{2}{*}{ Variable classification } & \multicolumn{3}{|c|}{ Men } & \multicolumn{3}{|c|}{ Women } \\
\hline & $\mathrm{HI}(-)$ & $\mathrm{HI}(+)$ & p-value & $\mathrm{HI}(-)$ & $\mathrm{HI}(+)$ & $p$-value \\
\hline \multicolumn{7}{|l|}{ Socioeconomic status } \\
\hline Age, y & $42.10 \pm 0.474$ & $63.7 \pm 1.136$ & $<0.001$ & $44.07 \pm 0.444$ & $64.5 \pm 1.549$ & $<0.001$ \\
\hline $20-29$ & $153(22.0)$ & - & $<0.001$ & $253(18.8)$ & $1(2.0)$ & $<0.001$ \\
\hline $30-39$ & $252(23.4)$ & $1(1.6)$ & & $449(22.7)$ & $8(6.6)$ & \\
\hline $40-49$ & $257(25.3)$ & $5(6.5)$ & & $427(24.3)$ & $8(5.5)$ & \\
\hline $50-59$ & $275(18.2)$ & $41(28.9)$ & & $437(18.8)$ & $58(26.9)$ & \\
\hline $60-69$ & $231(7.6)$ & $84(35.8)$ & & $320(8.9)$ & $60(25.0)$ & \\
\hline $70-79$ & $134(3.5)$ & $85(25.7)$ & & $219(6.4)$ & $84(31.0)$ & \\
\hline$\geq 80$ & $2(0.1)$ & $5(1.3)$ & & $6(0.1)$ & $5(3.0)$ & \\
\hline Hypertension & & & $<0.001$ & & & $<0.001$ \\
\hline Yes & $280(13.6)$ & $102(40.8)$ & & $420(14.8)$ & $100(42.0)$ & \\
\hline No & $1,020(86.4)$ & $115(59.2)$ & & $1,676(85.2)$ & $119(58.0)$ & \\
\hline Diabetes mellitus & & & $<0.001$ & & & $<0.001$ \\
\hline Yes & $116(5.4)$ & $45(14.9)$ & & $120(4.4)$ & $26(12.4)$ & \\
\hline No & $1,184(94.6)$ & $172(85.1)$ & & $1,976(95.6)$ & $193(87.6)$ & \\
\hline Education level & & & $<0.001$ & & & $<0.001$ \\
\hline$\leq$ Elementary & $183(8.6)$ & $86(36.8)$ & & $509(17.6)$ & $151(64.3)$ & \\
\hline Middle school & $128(7.5)$ & $44(17.4)$ & & $203(8.7)$ & $22(8.6)$ & \\
\hline High school & $497(45.5)$ & $59(36.0)$ & & $713(40.7)$ & $30(20.4)$ & \\
\hline$\geq$ College & $491(38.4)$ & $27(9.8)$ & & $665(32.9)$ & $15(6.7)$ & \\
\hline Household income & & & $<0.001$ & & & $<0.001$ \\
\hline Low & $162(9.3)$ & $71(23.4)$ & & $317(12.7)$ & $112(47.6)$ & \\
\hline Low-middle & $336(26.6)$ & $67(32.8)$ & & $549(26.8)$ & $46(20.8)$ & \\
\hline High-middle & $363(29.8)$ & $48(29.9)$ & & 579 (29.3) & $29(15.6)$ & \\
\hline High & $427(34.4)$ & $30(13.9)$ & & $650(31.1)$ & $33(16.0)$ & \\
\hline \multicolumn{7}{|l|}{ Hearing-related factors } \\
\hline Smoking & & & 0.001 & & & 0.36 \\
\hline Smoker & $507(43.1)$ & $54(33.4)$ & & $109(7.3)$ & $6(4.0)$ & \\
\hline Past smoker & $520(33.3)$ & $126(51.8)$ & & $104(6.3)$ & $11(4.6)$ & \\
\hline Non-smoker & $272(23.6)$ & $34(14.8)$ & & $1,880(86.4)$ & $201(91.4)$ & \\
\hline Tinnitus & & & $<0.001$ & & & $<0.001$ \\
\hline Yes & $252(16.9)$ & $92(43.5)$ & & $501(24.1)$ & $93(38.3)$ & \\
\hline No & $1,051(83.1)$ & $129(56.5)$ & & $1,604(75.9)$ & $131(61.7)$ & \\
\hline Occupational noise exposure & & & 0.22 & & & 0.62 \\
\hline Yes & $257(20.7)$ & $49(25.8)$ & & $186(9.1)$ & $14(7.7)$ & \\
\hline No & $1,042(79.3)$ & $172(74.2)$ & & $1,916(90.9)$ & $210(92.3)$ & \\
\hline Non-occupational noise exposure & & & 0.05 & & & 0.87 \\
\hline Yes & $27(2.8)$ & $11(6.6)$ & & $35(1.8)$ & $4(1.6)$ & \\
\hline No & $1,275(97.2)$ & 210 (93.4) & & $2,073(98.2)$ & 219 (98.4) & \\
\hline
\end{tabular}


in hearing-impaired cases showed the highest rate in the middle-to-low income class among men and the low-income class among women. In men, more than half of those with hearing impairment were past smokers. No statistical significance was found in either men or women with regard to a history of noise exposure at or outside the workplace and hearing loss (Table 1).

According to the AUDIT score, the hearing-impaired men consisted of $62.7 \%$ with appropriate drinking habits (grade I), $18.6 \%$ with risky drinking habits (grade II), and $18.7 \%$ with hazardous drinking habits (grade III). The rate of hazardous drinking (18.7\%) in men was higher in the hearing-impaired group than in the other group $(9.0 \%, p=0.002)$. Most female subjects were in AUDIT group I. With respect to the quantity of drinks consumed, most male subjects consumed more than 3 cups at one sitting, regardless of hearing status; this trend was not observed among women (Table 2).

Table $3 \mathrm{~A}$ shows the results of the logistic regression analysis with the dependent variables in which the AUDIT grade was the independent variable for men aged 20 years and older. According to the AUDIT grade, grade II subjects had a 0.516 times lower risk of hearing loss than grade I subjects [confidence interval (CI): 0.320 to 0.831 ]. Moreover, after adjusting for age, the risky drinking group (grade II) showed a decrease of 0.576 times compared with grade I subjects (CI: 0.338 to 0.981 ) but this was not significant after adjusting for all other variables. When adjusting for age, household income, education level, tinnitus, hearing loss, HTN, and DM, the odds ratio

Table 2. AUDIT grade according to hearing impairment status

\begin{tabular}{|c|c|c|c|c|c|c|}
\hline \multirow{2}{*}{ Variable classification } & \multicolumn{3}{|c|}{ Men } & \multicolumn{3}{|c|}{ Women } \\
\hline & $\mathrm{HI}(-)$ & $\mathrm{HI}(+)$ & p-value & $\mathrm{HI}(-)$ & $\mathrm{HI}(+)$ & $p$-value \\
\hline AUDIT & & & 0.002 & & & 0.18 \\
\hline Appropriate (grade I) & $722(57.8)$ & $139(62.7)$ & & $1,385(75.8)$ & $128(86.1)$ & \\
\hline Risky (grade II) & $410(33.2)$ & $35(18.6)$ & & $196(12.8)$ & $5(6.5)$ & \\
\hline Hazardous (grade III) & $105(9.0)$ & $20(18.7)$ & & $153(11.3)$ & $9(7.4)$ & \\
\hline Drinks per day & & & $<0.001$ & & & $<0.001$ \\
\hline $1-2$ & $221(14.5)$ & $59(25.5)$ & & 749 (34.5) & $76(35.9)$ & \\
\hline$\geq 3$ & $865(72.2)$ & $96(52.6)$ & & $590(34.0)$ & $21(10.6)$ & \\
\hline 0 & $213(13.3)$ & $59(22.0)$ & & $754(31.5)$ & $121(53.6)$ & \\
\hline
\end{tabular}

Table 3. Crude and multivariate adjusted ORs and $95 \%$ Cls for hearing impairment according to drinking patterns (AUDIT) (A) and moderate drinking (B) from the multinomial logistic regression analysis

\begin{tabular}{|c|c|c|c|}
\hline & Crude & Model I & Model II \\
\hline \multicolumn{4}{|l|}{ A. AUDIT } \\
\hline \multicolumn{4}{|l|}{ Men } \\
\hline Appropriate (grade I) & Reference & Reference & Reference \\
\hline Risky (grade II) & $0.516(0.320-0.831)^{*}$ & $0.576(0.338-0.981)^{*}$ & $0.581(0.335-1.003)$ \\
\hline Hazardous (grade III) & $1.908(0.984-3.700)$ & $2.353(1.031-5.370) *$ & $2.506(1.083-5.800) *$ \\
\hline \multicolumn{4}{|l|}{ Women } \\
\hline Appropriate (grade I) & Reference & Reference & Reference \\
\hline Risky (grade II) & $0.444(0.150-1.317)$ & $0.960(0.334-2.757)$ & $1.001(0.359-2.790)$ \\
\hline Hazardous (grade III) & $0.578(0.228-1.464)$ & $1.588(0.592-4.261)$ & $1.517(0.614-3.749)$ \\
\hline \multicolumn{4}{|l|}{ B. Drinks per day } \\
\hline \multicolumn{4}{|l|}{ Men } \\
\hline None & Reference & Reference & Reference \\
\hline $1-2$ drinks/day & $1.066(0.630-1.802)$ & $1.294(0.713-2.347)$ & $1.205(0.657-2.211)$ \\
\hline$\geq 3$ drinks/day & $0.442(0.285-0.686)^{*}$ & $1.297(0.776-2.166)$ & $1.277(0.752-2.171)$ \\
\hline \multicolumn{4}{|l|}{ Women } \\
\hline None & Reference & Reference & Reference \\
\hline $1-2$ drinks/day & $0.610(0.405-0.919)^{*}$ & $0.961(0.618-1.495)$ & $1.071(0.678-1.691)$ \\
\hline$\geq 3$ drinks/day & $0.182(0.099-0.335)^{*}$ & $0.722(0.371-1.407)$ & $0.813(0.424-1.560)$ \\
\hline
\end{tabular}

Model I: adjusted for age, Model II: adjusted for age, household income, education, tinnitus, smoking status, noise exposure, hypertension diagnosis, diabetes mellitus diagnosis. *p $\leq 0.05$. OR: odds ratio, Cl: confidence interval, AUDIT: Alcohol Use Disorder Identification Test 
(OR) was 2.506-fold higher among the group with hazardous drinking habits compared with the group with appropriate drinking habits (CI: 1.083 to 5.800). When all other variables were controlled for, the hearing-protective effect of risky drinking controlled for age was not significant. In women, no statistical correlation was found between the AUDIT grade and hearing loss. The results of the three hierarchical models for the amount of alcohol drinking at one time affecting hearing loss were not statistically significant. In the crude model analysis, more than three drinks in men and one or more drinks in women seemed to reduce the risk of hearing loss; however, there was no statistical significance in the confounder-adjusted Model I (age-adjusted) and Model II (age, household income, education, tinnitus, smoking status, noise exposure, and hypertension or diabetes mellitus diagnosis-adjusted) analyses (Table 3B).

\section{Discussion}

\section{Synopsis of key/new findings and comparisons with other studies}

The purpose of this study was to determine the degree to which alcohol drinking is a risk factor for hearing loss in adults 20 years of age and older and to determine how to prevent it.

Previous studies have shown that moderate drinkers (consuming one to two drinks per day) tend to have better health, in terms of lower rates of ischemic heart disease, lower rates of diabetes, and better hearing [16-19]. Moderate alcohol drinking increases high-density lipoprotein cholesterol and reduces vascular coagulation, which results in a cardiovascular protective effect. Hearing protection among moderate drinkers is also explained by the correlation with cardiovascular function and hearing [8,20,21]. In contrast, heavy alcohol consumption was associated with adverse cardiovascular effects and increased risk of hearing impairment [22].

As a result of this study, the rates of hearing loss in subjects without malignancy or chronic otitis media were $8.1 \%$ in men and $7 \%$ in women. Among drinkers, the AUDIT grade identified appropriate drinking (grade I) in 58.2\%, risky drinking (grade II) in 32.1\%, and hazardous drinking (grade III) in 9.7\% of men; in women, the classifications were $76.4,12.5$, and $11.1 \%$, respectively. The recent changes in women's social participation and the changed norms prohibiting women's drinking in Korean culture seem to have led to a higher hazardous drinking rate than that among men. This trend of an increase in problem drinking among women has been confirmed in previous studies [23].

After controlling for all variables, hazardous drinking (grade III) raised the risk of hearing loss significantly by 2.506 times compared to the reference standard. Risky drinking (grade II) according to the AUDIT classification, which was hearingprotective in the crude and Model I analyses, did not show a benefit after controlling for all other variables. Moreover, moderate drinking (1-2 drinks per day), which was known to be protective for hearing, did not result in hearing protection in both groups (Table 3).

The recent results suggest that the auditory benefits of moderate drinking cannot be assured for Koreans. In Koreans, vulnerability and susceptibility to harm from alcohol due to aldehyde dehydrogenase $(A L D H 2)$ gene polymorphisms should also be considered [24]. However, differences exist in the quantity of ethanol in " 1 drink" depending on the type of alcohol, such that there may not have been a correlation between the number of drinks per day and hearing loss. Although it does not fully reflect differences in the quantity of ethanol depending on the type of alcohol, AUDIT, an integrated scale including the amount of alcohol consumption and drinking patterns, complements the results of this study and has been proven as a predictive tool for hearing impairment in hazardous drinkers.

Another interesting result from this study was that hearing loss and AUDIT grade were not statistically related in women. The reason for this is that the drinking rate among women was relatively lower than that among men, and the survey does not exclude the possibility that women do not accurately report their drinking because of the social stigma. In fact, the proportion of hazardous drinkers among women drinkers was higher than the proportion among men drinkers. Therefore, it is possible that the reported drinking rates were lower than the actual rates. Furthermore, previous studies have shown gender differences with respect to alcohol metabolism, such that women exhibit reduced alcohol dehydrogenase activity [15,25]. The vulnerability of women to the effects of ethanol suggests that hazardous drinking may be associated with a greater risk of hearing loss in women. Thus, it is thought that studies on alcohol drinking and hearing loss in women alone need to be more accurate and detailed.

\section{Strengths of the study and clinical applicability of the study}

This study was a cross-sectional study, which has limitations in revealing direct relationships between drinking and hearing loss. In addition, drinking data as an independent variable was obtained from self-reported questionnaires, which may have resulted in information bias. However, this study used Korean National Health and Nutrition Survey data, which are nationwide data that represent Korean adults, to examine relationships between drinking and hearing loss in Koreans. Moreover, the diagnosis of hearing impairment, a dependent variable, was based on hearing data recorded by experts and 
was therefore very reliable as a measurement tool. Therefore, it is considered that there should be no great difficulty in generalizing the results to all adults in Korea. However, in a follow-up study, prospective cohort studies should be conducted to clarify direct and mutual relationships between these two factors. A longitudinal study to investigate harmful drinking and the mechanism of hearing loss should also be performed. The relationship between alcohol drinking and patterns of hearing loss (frequency-specific hearing loss, differences between ears in terms of symmetricity) requires further investigation. Moreover, further study should be attempted to determine the appropriate amount of alcohol for Koreans for hearing health preservation. The main implications of our results are that men with hazardous drinking habits were associated with hearing loss and that hearing health programs specialized for Korean drinking statuses should be developed.

In conclusion, hazardous drinking was associated with a higher risk of hearing loss in men than an appropriate level of drinking. Therefore, it is necessary to educate Koreans about proper drinking habits to promote hearing health.

\section{Conflicts of interest}

The authors have no financial conflicts of interest.

\section{REFERENCES}

1) Olusanya BO, Neumann KJ, Saunders JE. The global burden of disabling hearing impairment: a call to action. Bull World Health Organ 2014;92:367-73.

2) Emmett SD, Francis HW. The socioeconomic impact of hearing loss in U.S. adults. Otol Neurotol 2015;36:545-50.

3) Agrawal Y, Platz EA, Niparko JK. Prevalence of hearing loss and differences by demographic characteristics among US adults: data from the National Health and Nutrition Examination Survey, 19992004. Arch Intern Med 2008;168:1522-30.

4) Helzner EP, Patel AS, Pratt S, Sutton-Tyrrell K, Cauley JA, Talbott E, et al. Hearing sensitivity in older adults: associations with cardiovascular risk factors in the health, aging and body composition study. J Am Geriatr Soc 2011;59:972-9.

5) Rehm J, Mathers C, Popova S, Thavorncharoensap M, Teerawattananon Y, Patra J. Global burden of disease and injury and economic cost attributable to alcohol use and alcohol-use disorders. Lancet 2009;373:2223-33.

6) World Health Organization. The world health report 2002: reducing risks, promoting healthy life. Geneva: World Health Organization; 2002.

7) Saunders JB, Aasland OG, Babor TF, de la Fuente JR, Grant M. Development of the alcohol use disorders identification test (AUDIT): WHO collaborative project on early detection of persons with harm- ful alcohol consumption--II. Addiction 1993;88:791-804.

8) Dawes P, Cruickshanks KJ, Moore DR, Edmondson-Jones M, McCormack A, Fortnum H, et al. Cigarette smoking, passive smoking, alcohol consumption, and hearing loss. J Assoc Res Otolaryngol 2014; 15:663-74.

9) Choi YH, Park SK. Environmental exposures to lead, mercury, and cadmium and hearing loss in adults and adolescents: KNHANES 2010-2012. Environ Health Perspect 2017;125:067003.

10) Curhan SG, Eavey R, Wang M, Stampfer MJ, Curhan GC. Prospective study of alcohol consumption and self-reported hearing loss in women. Alcohol 2015;49:71-7.

11) Curhan SG, Eavey R, Shargorodsky J, Curhan GC. Prospective study of alcohol use and hearing loss in men. Ear Hear 2011;32:46-52.

12) Kang TS, Woo SW, Park HJ, Lee Y, Roh J. Comparison of genetic polymorphisms of CYP2E1, ADH2, and ALDH2 genes involved in alcohol metabolism in Koreans and four other ethnic groups. J Clin Pharm Ther 2009;34:225-30.

13) Helzer JE, Canino GJ. Alcoholism in North America, Europe, and Asia. New York: Oxford University Press;1992.

14) Erol A, Karpyak VM. Sex and gender-related differences in alcohol use and its consequences: contemporary knowledge and future research considerations. Drug Alcohol Depend 2015;156:1-13.

15) Baraona E, Abittan CS, Dohmen K, Moretti M, Pozzato G, Chayes ZW, et al. Gender differences in pharmacokinetics of alcohol. Alcohol Clin Exp Res 2001;25:502-7.

16) Arif AA, Rohrer JE. Patterns of alcohol drinking and its association with obesity: data from the Third National Health and Nutrition Examination Survey, 1988-1994. BMC Public Health 2005;5:126.

17) Gates GA, Cobb JL, D'Agostino RB, Wolf PA. The relation of hearing in the elderly to the presence of cardiovascular disease and cardiovascular risk factors. Arch Otolaryngol Head Neck Surg 1993; 119:156-61.

18) Rimm EB, Williams P, Fosher K, Criqui M, Stampfer MJ. Moderate alcohol intake and lower risk of coronary heart disease: meta-analysis of effects on lipids and haemostatic factors. BMJ 1999;319:1523-8.

19) Bell RA, Mayer-Davis EJ, Martin MA, D'agostino RB Jr, Haffner SM. Associations between alcohol consumption and insulin sensitivity and cardiovascular disease risk factors: the Insulin Resistance and Atherosclerosis Study. Diabetes Care 2000;23:1630-6.

20) Brant LJ, Gordon-Salant S, Pearson JD, Klein LL, Morrell CH, Metter EJ, et al. Risk factors related to age-associated hearing loss in the speech frequencies. J Am Acad Audiol 1996;7:152-60.

21) Mukamal KJ, Rimm EB. Alcohol consumption: risks and benefits. Curr Atheroscler Rep 2008;10:536-43.

22) Popelka MM, Cruickshanks KJ, Wiley TL, Tweed TS, Klein BE, Klein R, et al. Moderate alcohol consumption and hearing loss: a protective effect. J Am Geriatr Soc 2000;48:1273-8.

23) Kim W, Kim S. Women's alcohol use and alcoholism in Korea. Subst Use Misuse 2008;43:1078-87.

24) Shin MJ, Cho Y, Davey Smith G. Alcohol consumption, aldehyde dehydrogenase 2 gene polymorphisms, and cardiovascular health in Korea. Yonsei Med J 2017;58:689-96.

25) Frezza M, di Padova C, Pozzato G, Terpin M, Baraona E, Lieber CS. High blood alcohol levels in women: the role of decreased gastric alcohol dehydrogenase activity and first-pass metabolism. N Engl J Med 1990;322:95-9. 